\title{
An unusual occurrence of Pleomorphic adenoma involving the buccal minor salivary gland - A case report and literature review
}

SADJ June 2019, Vol. 74 No. 5 p236 - p238

K Rajkumar ${ }^{1}$, AS Singh ${ }^{2}$, CJ Perumal ${ }^{3}$, M Hainsworth $^{4}$

\section{INTRODUCTION}

Pleomorphic Adenoma (PA) is a benign tumour of salivary gland origin. PAs are found frequently in adult females between the $3^{\text {rd }}$ and $5^{\text {th }}$ decades of life. They frequently involve the parotid gland (53 - 77\%). ${ }^{1}$

The submandibular gland is affected in $44-68 \%$ of cases while only $6.4 \%$ of PAs are discovered in minor salivary gland sites. ${ }^{1}$ The most common sites for the occurrence of PAs in minor salivary glands are found in the palate (42.8 - 68.8\%), the upper lip (10.1\%), cheek (5.5\%), throat (2.5\%) and retromolar region $(0.7 \%){ }^{2}$

The anatomical contents of the buccal space includes adipose tissue, parotid duct, accessory parotid lobules, facial and buccal arteries, facial vein, lymphatic channels, branches of facial and mandibular nerves as well as minor salivary glands. ${ }^{3}$ This case is being reported due to the uncommon occurrence of pleomorphic adenoma within minor salivary glands.

\section{CASE REPORT}

A 23 year old male was referred to the Maxillofacial and Oral Surgery department at Grey's Hospital with the main complaint of an asymptomatic slow growing lesion on the left side of his face. The patient reported no medical history of any significance.

\section{Author affiliations:}

1. Kavir Rajkumar: BChD, Dip Odont (Oral Surgery), Division of Maxillofacial and Oral Surgery, Grey's Hospital, Pietermaritzburg, KwaZulu-Natal, South Africa.

ORCID Number: 000-0001-5351-672

2. Avin S Singh: BDS, MDent (MFOS), MSc, MDS, Head Division of Maxillofacial and Oral Surgery Grey's Hospital, Pietermaritzburg, KwaZulu-Natal, South Africa.

3. Colin J Perumal: BDS, MDent (MFOS), Division of Maxillofacial and Oral Surgery, Grey's Hospital, Pietermaritzburg, KwaZulu-Natal, South Africa.

4. Mike Hainsworth: MBCHB, MMed (Anat Path), Division of Anatomical Pathology Surgery, Grey's Hospital, Pietermaritzburg, KwaZulu-Natal, South Africa.

\section{Corresponding author: Kavir Rajkumar}

Division of Maxillofacial and Oral Surgery, Greys Hospital. P.O Box 138676, Cascades 3202, Pietermaritzburg, KwaZulu-Natal, South Africa.

Tel: +27 (0)837931913 Email: kavirraj@gmail.com

Author contributions:

1. Kavir Rajkumar: $33.3 \%$

2. AS Singh: $33.3 \%$

CJ Perumal: $33.3 \%$

4. M Hainsworth: $33.3 \%$
On examination the patient presented with a small oval $(4 \times 2 \times 2 \mathrm{~mm})$ mobile lesion, firm, non-pulsatile and non-fluctuant, which could be palpated beneath the buccal mucosa of the left buccal space (Figures 1A and $1 \mathrm{~B})$. The lesion was located on the left side of the face above the commissure of the mouth and below the ala of the nose, just posterosuperiorly to the upper lip. No enlarged lymph nodes were apparent.

The oral mucosa appeared to have an increased vascularity overlying the lesion (Figure $1 \mathrm{C}$ ). The skin overlying the lesion appeared normal with the mass easily slipping on bi-manual palpation. The differential diagnosis included foreign body granuloma, lymphadenitis, lymphoma, pleomorphic adenoma, nasolabial cyst, dermoid cyst, mucous retention cyst and lipoma.
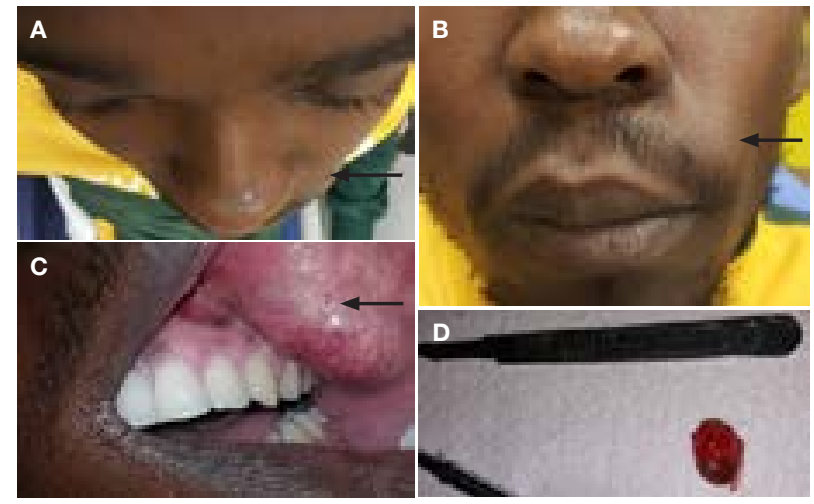

Figure 1.

Figure $1 \mathrm{~A}$ and $\mathrm{B}$ demonstrate the extra-oral view of lesion in the buccal space by arrows.

Figure $1 \mathrm{C}$ demonstrates the intra-oral view of the lesion.

Figure 1D demonstrates the size of the excised lesion in comparison to a Bard-Parker No. 3 scalpel handle.

\section{Treatment plan}

An intraoral surgical approach was conducted as this would allow access to the lesion without affecting the appearance of the patient.

An intraoral excisional biopsy was performed under local anaesthetic with the histology confirming a diagnosis of a pleomorphic adenoma. The patient was pleased with his now normal appearance and is scheduled for close follow-up visits in the future. 


\section{Histology report}

Histology revealed epithelial and a chondroid stromal components microscopically (Figure 2A). The lesion had a well circumscribed margin which showed a fine but incomplete fibrous capsule which appeared to abut on the excisional margins in small areas. These findings were consistent with a pleomorphic adenoma of minor salivary gland origin.

\section{DISCUSSION}

The anatomy of the buccal space lies deep to the zygomaticus major muscle. It is limited medially by the buccinator muscle, the superficial layer of the deep cervical fascia as well as the muscles of facial expression anteriorly and laterally, posteriorly by the masseter muscle, mandible, lateral and medial pterygoid muscles and the parotid gland.

There is no true superior and inferior border of the buccal space. The contents of the buccal space include: adipose tissue known as the buccal fat pad, parotid duct, minor salivary glands, accessory parotid lobules, facial and buccal arteries, facial vein, lymphatic channels as well as branches of the facial (cranial nerve VII) and mandibular nerves (cranial nerve $\mathrm{V}_{3}$ ). ${ }^{3}$

Pleomorphic adenomas (PAs) are the most common benign tumour of salivary gland origin. They are most frequently found in adult females between the $3^{\text {rd }}$ and $5^{\text {th }}$ decades of life and frequently involve the parotid gland $(53-77 \%){ }^{1}$

The submandibular gland is affected in $44-68 \%$ while only $6.4 \%$ of PAs are discovered in minor salivary gland sites. ${ }^{1}$ The most common sites for the occurrence of PA in minor salivary glands are found in the palate (42.8 - 68.8\%), the upper lip (10.1\%), cheek (5.5\%), throat $(2.5 \%)$, and retromolar region $(0.7 \%){ }^{2}$

This benign tumour is comprised of three components histologically; viz the epithelial, myoepithelial and a stromal or mesenchymal component. The identification of these three components is diagnostic of PA albeit in quantitative variations of the above.

Immunohistochemistry has aided in the differentiation of the different cell types within PAs. ${ }^{4}$ Recurrence of PAs has been documented due to spillage, inadequate removal or enucleation during surgical intervention. ${ }^{5}$

Khandekar et al. report a recurrence of 2-44\% of treated PAs. They recommend wide local excision with good safety margins, however intraoral lesions can be treated by extracapsular excision with 3-4 years of close patient follow-up. ${ }^{5}$ Ascani, Messi and Balercia reported a study of 347 PA of salivary glands in which no recurrences were found during the follow up period of 2-4 years.

This finding encourages pericapsular enucleation as a favourable treatment modality, achieving reduced morbidity without oncological compromise. ${ }^{6}$ In contrast Moore, Burkey and Netterville et al. recommend a wide excision including a cuff of normal healthy tissue as the treatment for benign salivary gland tumours as enucleation may not be adequate.

Recurrence maybe facilitated by pathological and surgical factors. The pathologic factors include: capsule thickness or lack of capsule, pseudopodia, satellite nodules and multi-centricity while surgical factors include: rupture of tumour, spillage of tumour contents, insufficient resection margins attributed to nerve branches and lastly inadequate excision related to the type of surgery. ${ }^{8}$

Special mention needs to be made of a significant but rare variant of PA called carcinoma ex pleomorphic adenoma which displays features of vascular invasion, focal dysplasia, and non-invasive (intracapsular) extent. ${ }^{9}$

Multiple recurrences and the size of the tumour may play a role in the malignant transformation of the PA. Malignant transformations may be suspected by clinical signs of sudden increase in size with pain, ulceration, spontaneous bleeding and tissue invasion. ${ }^{9}$

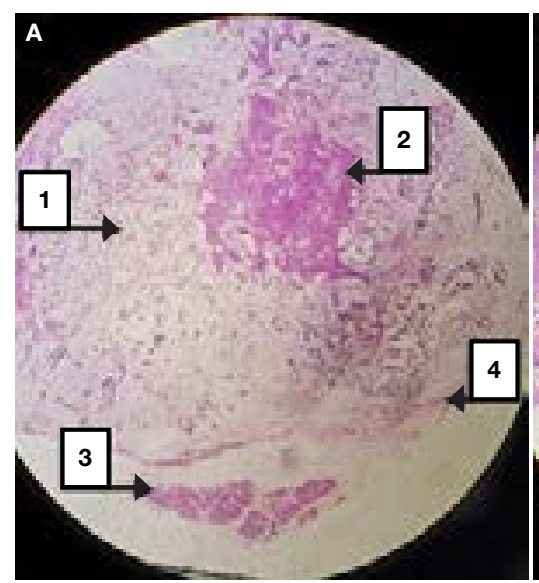

\section{Figure 2.}

Figure 2A: Low power photomicrograph of the specimen. Arrow 1 demonstrating chondroid stromal tumour component. Arrow 2 demonstrating epithelial tumour component. Arrow 3 demonstrating residual minor salivary gland. Arrow 4 demonstrating the fine tumour capsule.

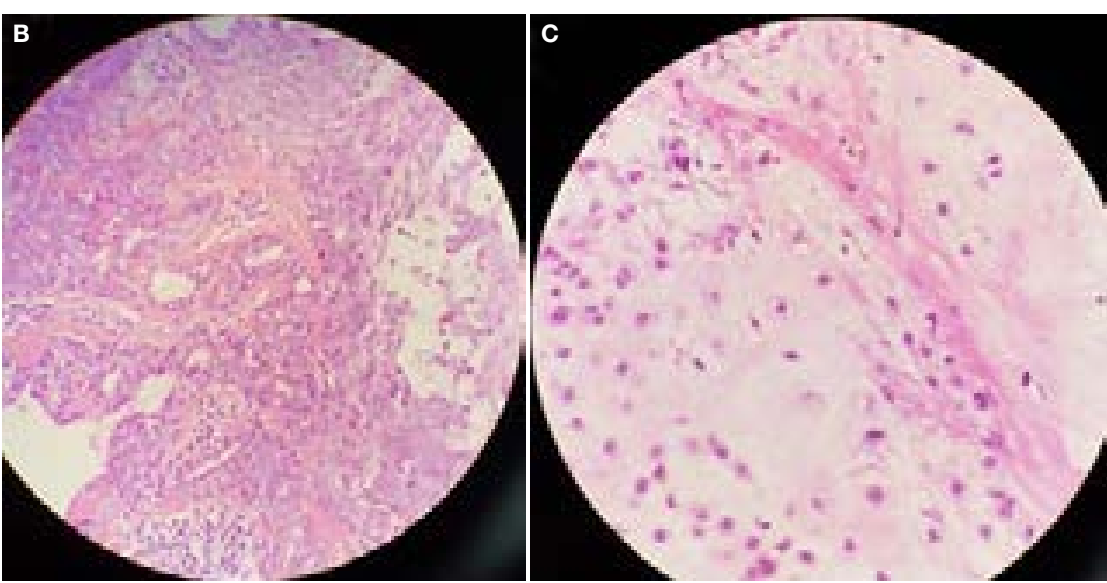

Figure 2B: High power photomicrograph of the specimen demonstrating epithelial component inclusive of well-formed glands.

Figure 2C: High power photomicrograph of chondroid stroma. 


\section{CONCLUSION}

Pleomorphic Adenomas rarely occur in the buccal space. This lesion demonstrated a fine but incomplete fibrous capsule adjacent to the excisional margins in small areas. Early removal of the lesion as in this case, with no further identifiable factors that could contribute to possible recurrence of the lesion, is advantageous. Despite this, long term follow-up is necessary where recurrence is a concern.

\section{References}

1. Verma P, Sachdeva SK, Verma KG, Sachdeva K. Pleomorphic adenoma of the cheek: A rare case report and review of literature. Indian J Dent Res. 2014; 25:122-4.

2. Pillai AK, Satpathy M, Nahar S, Moghe S. Pleomorphic adenoma in cheek: An uncommon finding. IJSS Case Reports \& Reviews 2014; 1(1):19-22.

3. Kim HC, Han MH, Moon MH, Kim JH, Kim IO, Chang KH. CT. MR Imaging of the buccal space: normal anatomy and abnormalities. Korean J Radiol. 2005; 22-30.

4. Panigrahi RG, Sahoo SR, Panda S. et al. Juvenile pleomorphic adenoma of the masticator space: The first case report. Contemp Clin Dent. 2013; 4(4):527-30.

5. Khandekar S, Dive A, Munde P, Wankhede ND. Pleomorphic adenoma of the buccal salivary gland. J Oral Maxillofac Pathol. 2015; 19(1):111-7.

6. Ascani G, Messi M, Balercia P. Surgical management of pleomorphic adenoma of the salivary glands: our experience. G Chir. 2008; 29(8-9):343-6.

7. Moore BA, Burkey BB, Netterville JL, Butcher RB, Amedee RG. Surgical management of minor salivary gland neoplasms of the palate. Ochsner J. 2008; 8(4):172-80.

8. Dulguerov P, Todic J, Pusztaszeri, Alotaibi NH. Why do parotid pleomorphic adenomas recur? A systemic review of pathological and surgical variables. Front. Surg. 2017; 4(26):1-8.

9. Perumal CJ, Meyer M, Mahomed A. A Giant pleomorphic adenoma of the submandibular salivary gland: A case report. Craniomaxillofac Trauma Reconstr. 2012; 5(3):185-8.

\section{Do the CPD questionnaire on page 262}

The Continuous Professional Development (CPD) section provides for twenty general questions and five ethics questions. The section provides members with a valuable source of CPD points whilst also achieving the objective of CPD, to assure continuing education. The importance of continuing professional development should not be underestimated, it is a career-long obligation for practicing professionals.

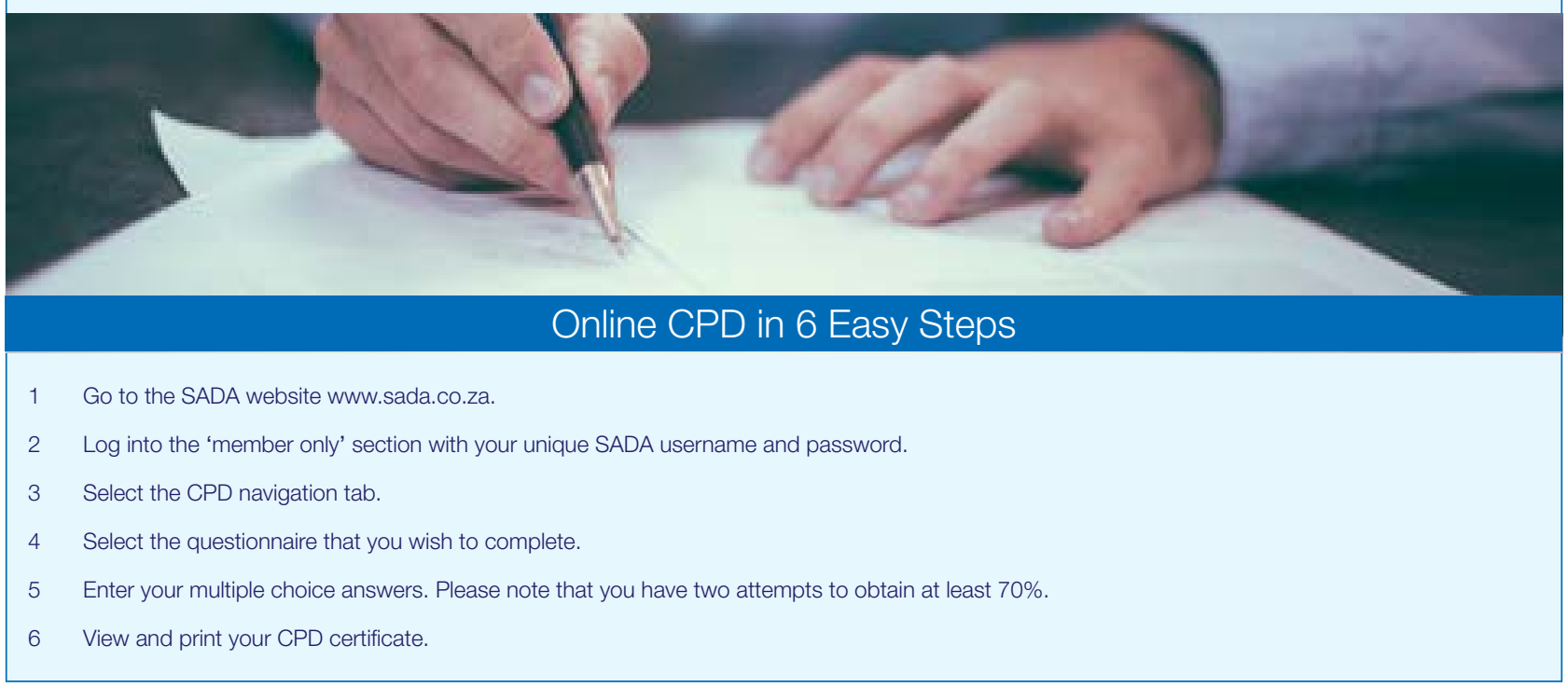

